\title{
Modelling the relationship between canopy projection area and above-ground carbon stock of intermingled canopy trees using high-resolution satellite imagery
}

\begin{abstract}
S. K. Shah ${ }^{1^{*}}$ and H. Acharya ${ }^{1}$
This study was aimed to establish regression models for the relationship of Canopy Projection Area (CPA) with carbon stock of intermingled canopy trees of dominant species for the prediction of above-ground carbon stock. Manual delineation of CPA of intermingled canopy trees of the dominant species was carried out using GeoEye Satellite Image. Diameter at breast height of trees were measured in 56 sample plots. The above-ground dry biomass of trees was calculated from the field measured DBHs using allometric equation while the above-ground carbon stock of the trees were obtained by multiplying their dry biomass with the factor 0.47 . Individual basal area of intermingled canopy trees was calculated separately and was summed up ( $\Sigma B A)$ along with the summation of their carbon stock ( $\Sigma$ carbon). Correlation analysis was carried out to assess the linear relationship between CPA, DBH, BA, biomass, and carbon stock. Four types of functions, viz., simple linear, quadratic, logarithmic and power were used to fit the data using least square regression method. Shorea robusta, Schima wallichii and Terminalia alata were found dominant tree species in the study area. The relationship of CPA with $\Sigma B A$ and $\Sigma$ carbon of intermingled canopy trees of Shorea robusta was found to be linear with $R^{2}$ of 0.29 and 0.25 respectively. Simple linear regression model resulted in the least error for the prediction of carbon stock of intermingled canopy trees. The identified simple linear regression models having the least error are not applicable for the prediction of above-ground tree carbon stock of broadleaf forest in hilly terrain.
\end{abstract}

Key words: Crown projection area, intermingled canopy trees, basal area, biomass, above-ground carbon stock, GeoEye Satellite Image

$\mathrm{F}$ orest has an important role in global carbon cycle that covers over one-fourth of the world's geographical area. It accounts for 289 gigatonnes (Gt) of carbon in its biomass (FAO, 2013). Nevertheless, deforestation and degradation of forest especially in developing countries for agriculture are causing 20-25 per cent carbon emission (CIFOR et al., 2009). Abatement of forest-based emission is critical to limit global warming that contributes to unprecedented climate change. REDD and REDD + mechanism have become central efforts to combat climate change due to anthropogenic activities in developing countries (UNFCCC, 2010). In addition, forest carbon would be traded as commodity goods in an emerging international voluntary carbon market to offset carbon emission by corporate or business houses
(Gibbs et al., 2007). Different methods have been piloted and tested to estimate forest carbon at large scale that requires for effective implementation of REDD+ and carbon trade among others. Highresolution satellite image has been researched for the estimation of forest carbon using regression models.

Remote Sensing (RS) has been used as an important technique to estimate biomass at a larger scale. It acquires data using different sensors, e.g., Optical or Radio Detection and Ranging (Radar) or Light Detection and Ranging (LiDAR) aboard satellite or aircraft. The strengths of the techniques are to provide spatially explicit information and repeated coverage including the possibility of covering large areas as well as remote areas that may be difficult to access. Three major RS techniques have been evolved

\footnotetext{
${ }^{1}$ Department of National Parks and Wildlife Conservation, Babarmahal, Kathmandu.

* Corresponding author: shyamkumar_shah@yahoo.com
} 
to estimate forest carbon, viz. i) Optical RS, ii) Radar RS and iii) LiDAR RS.

High resolution satellites such as Quick Bird, IKONOS and World View are capable of sensing biophysical parameters of trees such as crown dimension which correlate directly with biomass (Gonzalez et al., 2010). High resolution satellite data have become available anywhere in the world because of rapid advances and decreasing cost (Asner, 2009). The cost is further justifiable for the initial carbon stock estimation and to meet Intergovernmental Panel on Climate Change IPCC 'Tier 3' standard which ensures the higher level of accuracy and lower level of uncertainty (Patenaude et al., 2005). It has potential to higher financial returns for monitoring and verifying carbon stock and emissions (Gibbs et al., 2007).

This study investigated the relationship between Canopy Projection Area (CPA) of intermingled canopy trees manually delineated from the image and their above-ground carbon stock using correlation and regression analysis. The intermingled canopy trees can be defined as a group of trees whose canopies overlap or mix together. Individual tree in intermingled canopies has the competition for crown expansion from the branches of adjoining trees. Regression models were established using CPA as a predictor for the prediction of above-ground carbon stock of intermingled canopy trees.

\section{Materials and methods}

\section{Study area}

This study was carried out in Khayarkhola Watershed located in Chitwan District of Central Nepal (Fig. 1). The area is characterized by subtropical broadleaved forest with Shorea robusta as the dominant species. Major associate species are Terminalia alata, Terminalia bellirica, Lagerstroemia parviflora, Schima wallichii, Semicarpus anacardium and Mallotus philippensis. There were 15 community forests in the area. The area is drained by Khayarkhola Stream having many small tributaries feeding into it. The climate is subtropical monsoon with average annual precipitation of $1,830 \mathrm{~mm}$. Annual mean temperature is $24^{\circ} \mathrm{C}$ that ranges from $18^{\circ} \mathrm{C}$ to $36^{\circ} \mathrm{C}$ (Panta et al., 2008). The altitude of the site ranges from $300 \mathrm{~m}$ to $1,200 \mathrm{~m}$ above mean sea level.

\section{Research hypothesis}

Ho: There is no significant ( $95 \%$ confidence level) relationship between the CPA and the $\Sigma \mathrm{BA}$, the CPA and the $\Sigma$ biomass, the CPA and the $\Sigma$ carbon of two or more intermingled- canopy trees.

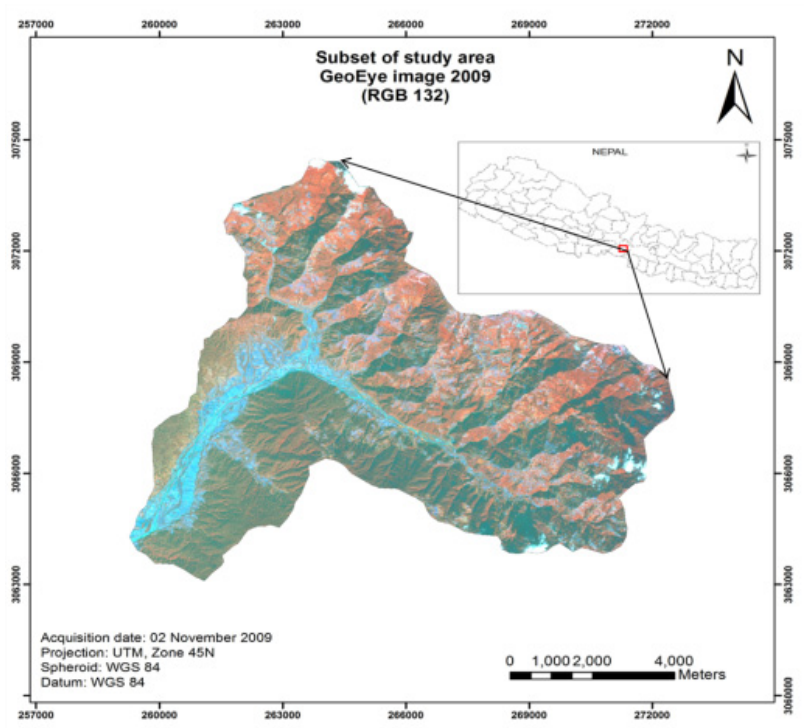

\section{Fig. 1: The study area, Chitwan District of} Central Nepal

\section{Field data collection}

Stratified random sampling was followed to design sample plot (Mitchell and Popovich, 1997). Individual community forest was considered as a stratum. The sample size was calculated at probability level of $5 \%$ and allowable error of $10 \%$. The sample size was allocated to the individual community forests proportional to their areas and at least two sample plots were maintained in each stratum; altogether, 63 sample plots were laid out. Sample plots to each stratum were located randomly using ArcGIS 2010.

At sample plot location, circular plots with $12.62 \mathrm{~m}\left(500 \mathrm{~m}^{2}\right.$ area) radius were demarcated (Husch et al., 2003). Within the circular plot, DBH $(\geq 10 \mathrm{~cm})$ of intermingled canopy trees recognized in the image (Brown, 2002; Clark and Clark, 2000) were measured and coordinates were recorded using iPAQ. Measurement of trees was carried out in 56 sample plots out of the total 63 sample plots. The remaining sample plots could not be reached due to inaccessible terrain and time limitation.

\section{CPA delineation}

Orthorectified GeoEye images acquired on 02 November, 2009 were used. The panchromatic 
image of spatial resolution $0.50 \mathrm{~m}$ and MSS images of spatial resolution $2 \mathrm{~m}$ were fused using ERDAS IMAGINE 2010. The $3 \times 3$ low pass filter was applied to the fused image to enhance image information content. Filtered images were rotated to $180^{\circ}$ to have better view of tree crown. Sample plot shapefile and tree point shapefile were overlaid in the image. The CPA of intermingled canopy trees was digitised at 1:250 scale manually using polygon construction tool in ArcGIS 2010. There was about 10-11 months lag between image acquisition and field data collection. Data was collected in September-October, 2010. It was assumed that diameter at breast height (DBH) of the tree $(\geq 10 \mathrm{~cm})$ would not have increased significantly in the period.

\section{Data analysis}

The above-ground dry biomass of intermingled canopy trees of the dominant species was calculated from their field-measured DBHs using allometric equation. Among the biophysical parameters of trees, DBH is an important predictive variable (Leboeuf et al., 2007) which alone explains more than $95 \%$ variation in biomass (Gibbs et al., 2007). Biomass of all trees in one intermingled canopy group was summed up ( $\Sigma$ biomass). The total carbon ( $\Sigma$ carbon) of intermingled canopy trees was calculated from इbiomass using the conversion factor 0.47 (IPCC, 2006). Individual basal area of interminlged canopy trees of the dominant species were calculated from their DBHs separately using the formulae (Hedl et al., 2009). Basal area of all the trees in one intermingled group was summed up ( $\Sigma \mathrm{BA})$.

The data were observed in scatter plot using CPA as the predictor and $\Sigma \mathrm{BA}, \Sigma$ biomass, $\Sigma$ carbon as response variables. Scatter plots can reveal nonlinearity, suspected outlier and unequal variance. The dataset were randomly divided into two sets: $60 \%$ for model building and another $40 \%$ for model validation after excluding the outliers (Gill et al., 2000). Pearson's productmoment correlation coefficient was calculated to see the strength of linear relationship between

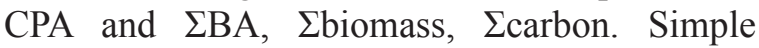
linear, quadratic, logarithmic and power function were used to develop regression models for the relationship of CPA with $\Sigma \mathrm{BA}$, $\Sigma$ biomass, $\Sigma$ carbon. The significances of regression coefficients were assessed by t-statistic and the significance of regression models were assessed by F-statistics at $95 \%$ confidence level. Root mean square error (RMSE) was used for the comparison of predictive accuracy of the models (Gill et al., 2000). The identified significant model based on F-statistics were validated using $40 \%$ independent dataset for the calculation of RMSE.

\section{Results and discussion}

A total of 146 trees of 12 different species were found in a two-intermingled canopy situation in the sample plots in the field. Out of total the two-intermingled canopy trees, 122 trees were pure intermingled canopy trees and the rest 24 were mixed (different species) intermingled canopy trees. A total of 6 species, namely, Adina cordifolia, L. parviflora, S. wallichii, S. anacardium, S. robusta and T. alata were found to have occurred in pure intermingled canopy situation. The other 6 species were intermingled with different species. In the category twointermingled, $S$. robusta species had the largest number followed by $S$. wallichii and T. alata.

The dominant S. robusta trees were found to be in pure intermingled canopy situation with two trees, three trees and four trees. The set of two, three, and four intermingled canopies were 51, 23 and 2 respectively. The total number of trees resulted in 102, 69 and 8 trees with two, three and four intermingled canopy situation respectively (Fig. 2). No other species were found to be in pure intermingled canopy situations especially with more than two trees. The two and three intermingled trees of $S$. robusta was the only trees taken for analysis. The two and three-intermingled canopy trees were treated as one set of data as it was not possible to differentiate between two and three-intermingled canopy situations in satellite image.

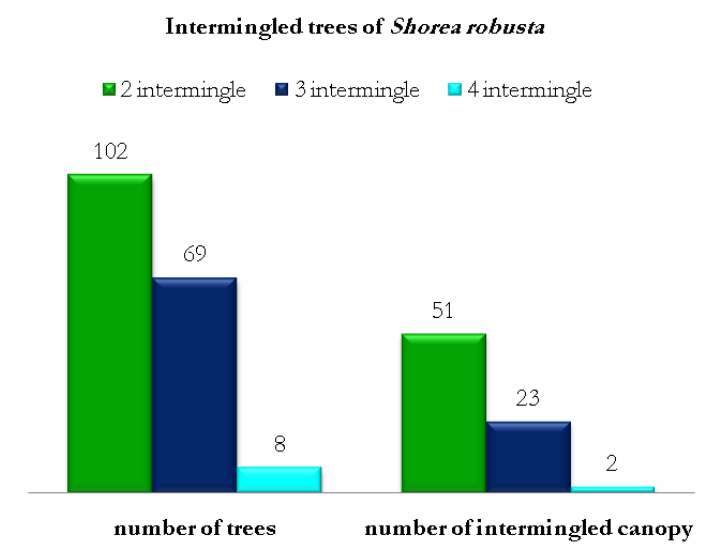

Fig. 2: Number of intermingled canopy trees of $S$. robusta 


\section{Exploratory data analysis}

The descriptive statistics of $\Sigma \mathrm{BA}$, $\Sigma$ biomass, $\Sigma$ carbon and CPA of intermingled (two and three together) canopy trees of $S$. robusta are presented after removing outliers in table 1.

\section{Correlation analysis}

Pearson's correlation coefficient was calculated using R software to analyse the strength of linear relationship of $\Sigma$ BA with $\Sigma$ biomass and $\Sigma$ carbon. The correlation of $\Sigma$ BA with $\Sigma$ biomass and

Table 1: Descriptive statistics of $\Sigma$ BA, $\Sigma$ biomass, $\Sigma$ carbon and CPA of intermingled canopy trees of $S$. robusta

\begin{tabular}{lrrrrrr}
\hline & $\begin{array}{r}\text { Species } \\
\text { number }\end{array}$ & Minimum & Maximum & Mean & Std. deviation & Std. error \\
\hline Basal area $\left(\mathrm{cm}^{2}\right)$ & 74 & 733.91 & 14950.75 & 4559.42 & 2424.87 & 281.88 \\
Biomass $(\mathrm{kg})$ & 74 & 335.56 & 12117.83 & 2966.26 & 1913.55 & 222.45 \\
Carbon $(\mathrm{kg})$ & 74 & 157.72 & 5695.38 & 1394.14 & 899.37 & 104.55 \\
CPA $\left(\mathrm{m}^{2}\right)$ & 74 & 48.10 & 252.53 & 122.87 & 46.316 & 5.38 \\
\hline
\end{tabular}

Graphical analysis of the relationship between CPA, BA, biomass and carbon using scatter plot

The scatter plots of explanatory variable CPA with response variables $\Sigma \mathrm{BA}$ and $\Sigma$ carbon of two and three intermingled trees of $S$. robusta are shown in figure 3. The overall pattern of the scatter plots show that there was positive linear relationship of CPA with $\Sigma$ BA and $\Sigma$ carbon. Nonlinear pattern was not found distinctly. The strength of relationship between them would be confirmed by calculating correlation coefficient.
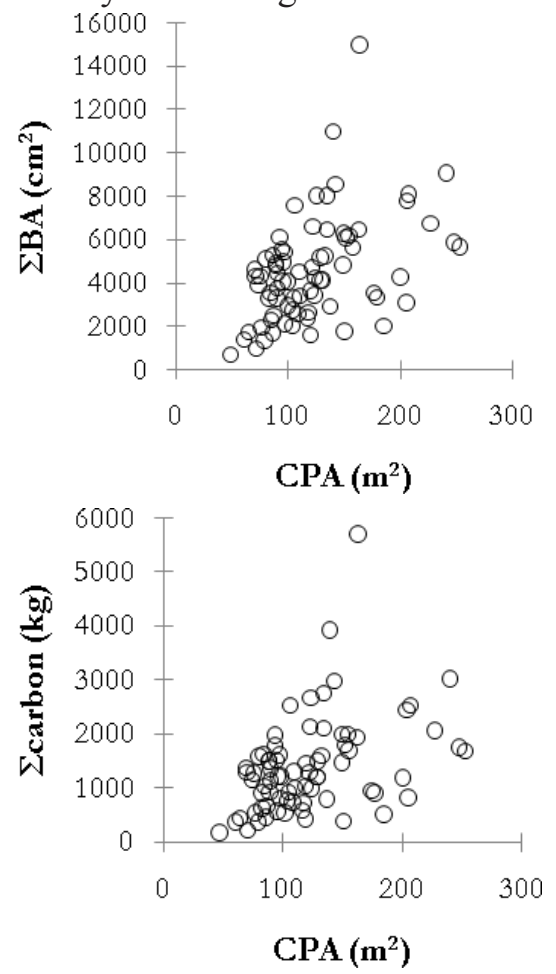

Fig. 3: Scatter plot of CPA with $\Sigma B A$ and $\Sigma$ carbon of intermingled canopy trees of $S$. robusta
$\Sigma$ carbon are presented in table 2 . The correlation of $\Sigma$ BA with $\Sigma$ biomass and $\Sigma$ carbon was found to be highly significant $(p \leq 0.001)$. In addition, the calculated $t$-values are higher than tabulated $\mathrm{t}$-values at 5\% significance level (Winer, 1962). According to t-test, the null hypothesis is rejected. Therefore, there is significant relationship between the CPA and $\Sigma \mathrm{BA}$, the CPA and $\Sigma$ biomass, the CPA and $\Sigma$ carbon of two and threeintermingled canopy trees. However, the strength of linear relationship between them was not found to be strong $(<0.7)$. The tabulated t-values for 40 degrees of freedom are taken into account as $\mathrm{t}$-values are mentioned for 40 and 50 degrees of freedom in student's t distribution table and the tvalues are not mentioned for degrees of freedom between 40 and 50 (Winer, 1962).

\section{Regression analysis}

Table 3 shows the regression models for the relationship of CPA with $\Sigma$ BA, $\Sigma$ biomass and $\Sigma$ carbon of $S$. robusta. The randomly divided $60 \%$ dataset were used to fit linear, quadratic and logarithmic function regression models using SPSS Software. Similarly, power function regression model was developed from the data using XLSTAT 2010 Software. The regression models were validated using $40 \%$ independent dataset. The regression coefficients of quadratic and power function models were found to be not significant. The power function was not taken for further analysis whereas the quadratic function model was taken because of deliberate introduction of collinearity between CPA and CPA2. The simple linear, quadratic and logarithmic models 


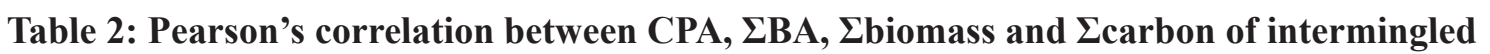
canopy trees of $S$. robusta

\begin{tabular}{|c|c|c|c|c|c|c|c|}
\hline \multirow{2}{*}{ Species } & \multirow{2}{*}{ Variables } & \multirow{2}{*}{$\mathbf{t}$} & \multirow{2}{*}{ df } & \multicolumn{3}{|c|}{$95 \%$ confidence } & \multirow{2}{*}{ P-value } \\
\hline & & & & 1 & & limit & \\
\hline \multirow{3}{*}{$\begin{array}{l}\text { Sal (S. robusta) } \\
\text { (Intermingled } \\
\text { canopy trees) }\end{array}$} & $\mathrm{CPA}$ and $\Sigma \mathrm{BA}$ & 4.096 & 41 & 0.54 & 0.285 & 0.722 & $<0.001$ \\
\hline & $\begin{array}{l}\text { CPA and } \\
\text { Sbiomass }\end{array}$ & 3.673 & 41 & 0.50 & 0.234 & 0.694 & $<0.001$ \\
\hline & $\begin{array}{l}\text { CPA and } \\
\sum \text { carbon }\end{array}$ & 3.673 & 41 & 0.50 & 0.234 & 0.694 & $<0.001$ \\
\hline
\end{tabular}

The correlation results rejected the hypothesis - Ho: There is no significant ( $95 \%$ confidence level) relationship between the CPA and $\Sigma \mathrm{BA}$, the CPA and $\Sigma$ biomass, the CPA and $\Sigma$ carbon of two and threeintermingled canopy trees.

Table 3: Regression models with the calibration and validation statistics for the relationship of CPA with $\Sigma$ BA, $\Sigma$ biomass and $\Sigma$ carbon of intermingled canopy trees of $S$. robusta

\begin{tabular}{|c|c|c|c|c|c|c|}
\hline \multirow{2}{*}{$\begin{array}{l}\text { Regression } \\
\text { models }\end{array}$} & \multicolumn{3}{|c|}{ Constants } & \multirow{2}{*}{$\begin{array}{c}\text { Calibration } \\
(\mathrm{N}=43) \\
\mathbf{R}^{2}\end{array}$} & \multicolumn{2}{|c|}{ Validation $(\mathrm{N}=\mathbf{2 9})$} \\
\hline & $\mathbf{a}$ & b & c & & RMSE & RMSE \% \\
\hline $\mathrm{BA}=\mathrm{a}+\mathrm{b} \cdot \mathrm{CPA}$ & $2073.45 * *$ & $20.90 * * *$ & & 0.29 & 1896.28 & 49.25 \\
\hline $\begin{array}{l}\mathrm{BA}=\mathrm{a}+\mathrm{b} \\
\mathrm{CPA}+\mathrm{c} . \mathrm{CPA} 2\end{array}$ & -747.32 & $63.80^{*}$ & -0.14 & 0.29 & 1940.80 & 50.40 \\
\hline $\begin{array}{l}\mathrm{BA}=\mathrm{a}+\mathrm{b} . \\
\ln (\mathrm{CPA})\end{array}$ & $-9700.66^{* *}$ & $3025.203 * * *$ & & 0.33 & 1902.23 & 49.40 \\
\hline $\mathrm{BA}=\mathrm{a} \cdot \mathrm{CPAb}$ & 298.27 & $0.57^{*}$ & & \multicolumn{3}{|c|}{ coefficient not significant $(p>0.05)$} \\
\hline $\begin{array}{l}\text { Biomass }=\mathrm{a} \\
+\mathrm{b} . \mathrm{CPA}\end{array}$ & $1221.25^{*}$ & $14.51 * * *$ & & 0.25 & 1407.18 & 58.52 \\
\hline \multirow{2}{*}{$\begin{array}{l}\text { Biomass }=a+b \\
\text { CPA }+\mathrm{c} . \text { CPA } 2\end{array}$} & -985.447 & $48.074 *$ & -0.109 & 0.25 & 1453.34 & \\
\hline & 60.62 & & & & & \\
\hline $\begin{array}{l}\text { Biomass }=a+b \\
\ln (\mathrm{CPA})\end{array}$ & $-7048.59 * *$ & $2120.59 * * *$ & & 0.28 & 1415.22 & 58.85 \\
\hline $\begin{array}{l}\text { Biomass } \\
=\mathrm{a} . \mathrm{CPAb}\end{array}$ & 163.223 & $0.6095 *$ & & \multicolumn{3}{|c|}{ coefficient not significant $(p>0.05)$} \\
\hline $\begin{array}{l}\text { Carbon }=a \\
+b . C P A\end{array}$ & $573.99 *$ & $6.82 * * *$ & & 0.25 & 661.39 & 58.52 \\
\hline $\begin{array}{l}\text { Carbon }=a+b \\
\text { CPA }+ \text { c.CPA2 }\end{array}$ & -463.16 & $22.595^{*}$ & -0.051 & 0.25 & 685.25 & 60.62 \\
\hline $\begin{array}{l}\text { Carbon }=a+b \\
\ln (\text { CPA })\end{array}$ & $-3312.839 * *$ & $996.675^{* * *}$ & & 0.28 & 665.15 & 58.85 \\
\hline $\begin{array}{l}\text { Carbon }= \\
\text { a.CPAb }\end{array}$ & 76.715 & $0.610^{*}$ & & \multicolumn{3}{|c|}{ coefficient not significant $(p>0.05)$} \\
\hline
\end{tabular}

For quadratic function model, adjusted $\mathrm{R}^{2}$ is mentioned because $\mathrm{R}^{2}$ get inflated by increasing the parameters in the model. In the other models, $R^{2}$ is mentioned since they have only one parameter. Significance levels are $p \leq 0.05^{*}$, $\mathrm{p} \leq 0.01^{* *}$, and $\mathrm{p} \leq 0.001^{* * *}$. Regression coefficients were tested for significance $(\mathrm{p} \leq 0.05)$ using $\mathrm{t}$ test. 
were found to be significant $(\mathrm{p} \leq 0.05)$ based on F statistics. The simple linear model was found to have the least error for prediction of carbon compared to the other function models.

\section{Scatter plots with the linear regression equations}

Regression equations with coefficients of determination are shown in scatter plots (Fig. 4) for the selected simple linear models. The scatter plots revealed that relationships between the parameters were weak. These plots do not show any distinct nonlinear pattern.

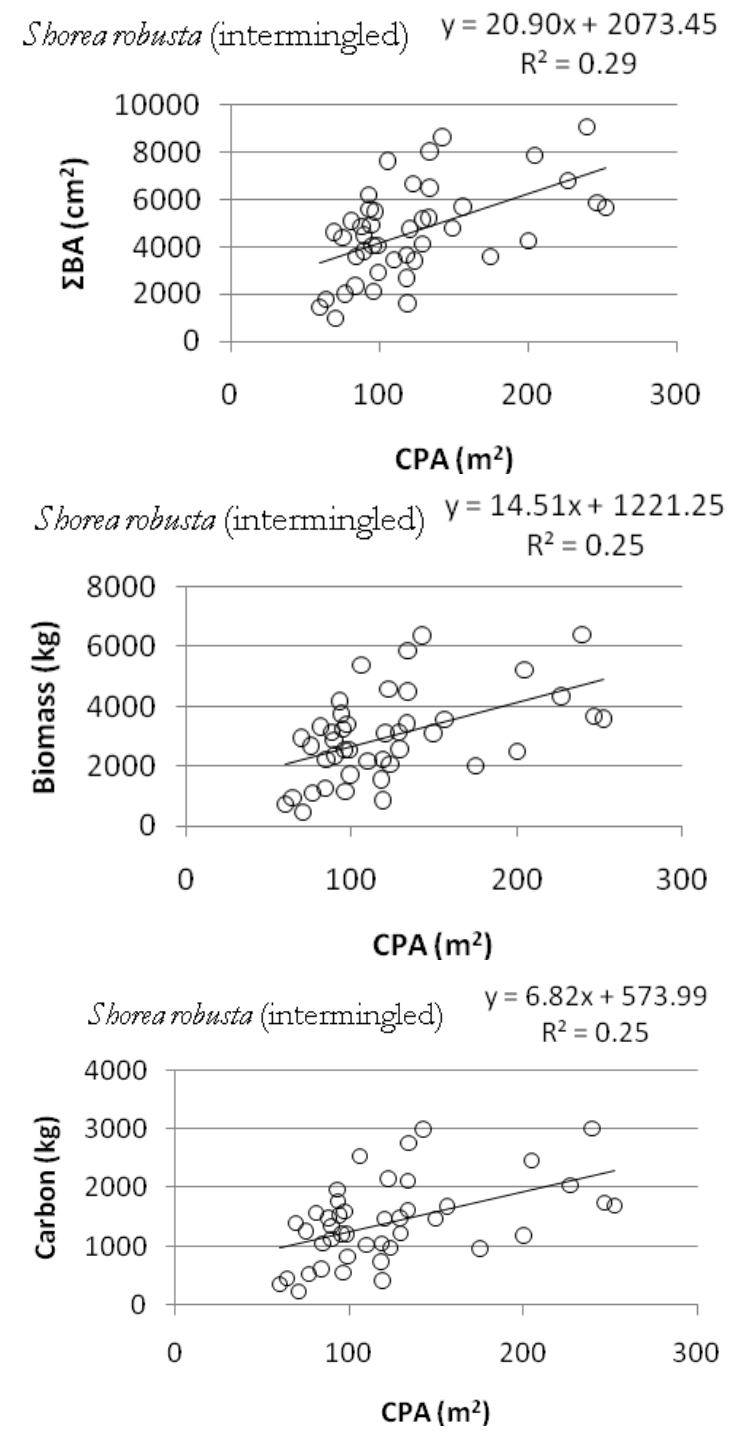

Fig. 4: Linear regressions of $\Sigma B A, \Sigma b$ biomass and $\Sigma$ carbon on CPA of intermingled canopy trees of $S$. robusta

The regression coefficients of power function models were not found to be significant $(p \leq 0.05)$. This suggested that there was no significant and strong power function relation between the parameters. The regression coefficients in simple linear and logarithmic were found to be significant $(\mathrm{p} \leq 0.05)$. However, the coefficients in quadratic model were not found to be significant. This could be because of deliberate introduction of collinearity between CPA and CPA2. Based on the lowest value of RMSE, the regression results suggested simple linear relationship between CPA, $\Sigma$ BA, $\Sigma$ biomass and $\Sigma$ carbon separately (Table 3 ). The scatter plots of regression equations do not show any distinct nonlinear pattern between the parameters.

The CPA and $\Sigma$ BA relation was found to be comparable with the study done by Mitchell and Popovich (1997). He analysed the relationship between basal area of trees per unit land area and canopy cover (\%) in Ponderosa pine forest and demonstrated a straight line relationship between them below 60\% canopy. Bartelink (1996) also found the linear relationship between CPA and BA of Douglas fir in single tree situation, whereas this study found a linear relationship between $\mathrm{CPA}$ and $\Sigma \mathrm{BA}$ in intermingled canopy trees. Simple linear relationship was shown applicable to the above-ground biomass estimation (ton/ha) of forest stands using BA $\left(\mathrm{m}^{2} / \mathrm{ha}\right)$ of forest stands (Chiba, 1998). However, there is no literature available that investigated the relationship between CPA, $\Sigma$ BA and $\Sigma$ biomass or $\Sigma$ carbon in intermingled canopy situation. In order to explain the query, why linear relationship was found between $\Sigma \mathrm{BA}$ and CPA in intermingled canopy situation? The authors would like to strengthen their understanding based on field experiences and some logic. It is important to understand stand alone and intermingled canopy trees situation in the field. The stand alone and two-intermingled trees are shown in figure 5. The degree of intermingle has not been taken into account. Once tree canopies were not visible as stand alone (completely separated canopy from any other canopies surrounding to it), those were considered as intermingle canopy even without their branches considerably intermixed together like in the situation in figure 5. This degree of intermingle affects the CPA considerably but has no effect on the DBH.

Another important factor could be the competition or crowding between the trees. Trees crown development was found to be negatively affected by competition from neighbouring tree crowns (Larocque, 2000). It is reasonable to assume 
that a group of intermingled canopy trees is similar to a stand alone in terms of competition and CPA. When branches of trees touch or intermingled with one another, they fall under intermingled group. Since the forest in the study area did not have $100 \%$ canopy cover, most of the intermingled trees were isolated as a group without competition from surrounding trees. It can be assumed that due to the intra competition within intermingled canopy trees for canopy expansion, they start extending canopy on edges in order to compensate for the overlap area. This is shown in figure 5 where they are extending their canopies even with larger area than the overlapped one. It is thus plausible that canopy area is still growing without diminishing the rate of growth when we consider CPA of intermingled group as a whole.

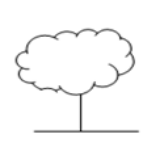

(a)

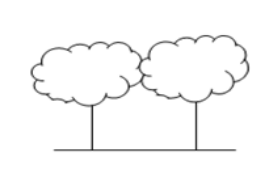

(b)

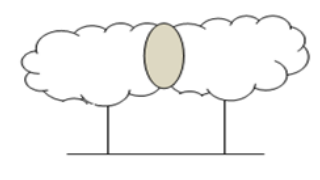

(c)
Fig. 5: (a) Stand alone trees; (b) and (c) Twointermingled canopy trees

Following the logic mentioned in above paragraph for CPA and $\Sigma$ BA relation, the linear relationship between CPA and $\Sigma$ biomass or $\Sigma$ carbon is also maintained. Further, it appears that intracompetition in intermingled situation affects individual canopy area as well as diameter of trees. As a result, different sizes (DBH) of trees are found in the intermingled group. Therefore, the sum of carbon of all individual trees relate linearly with their intermingled canopy area.

\section{Model comparison and error in prediction of carbon}

The difference of RMSE between the three regression models, viz., simple linear, quadratic and logarithmic in intermingled canopy trees of $S$. robusta was not large. Nonetheless, simple linear regression model was found to predict, viz., $\Sigma B A$, $\Sigma$ biomass or $\Sigma$ carbon with the least error (Table 4).

The prediction of carbon from CPA was found to have high error with RMSE $58.52 \%$ (Table 4). This error increased substantially compared to the prediction of basal area, i.e., from $49.25 \%$ to $58.52 \%$ (Table 4 ). It is further evident that the use of allometric equation for the calculation of biomass is an important factor for this incremental error including the error in the vertical projection area of CPA in the image and CPA delineation.

Table 4: Predictive accuracy of different models for intermingled canopy trees of $S$. robusta

\begin{tabular}{lrrrr}
\hline \multirow{2}{*}{ Models } & \multicolumn{2}{c}{ CPA versus $\mathbf{\Sigma}$ BA } & \multicolumn{2}{c}{ CPA versus $\Sigma$ carbon } \\
\cline { 2 - 5 } & $\begin{array}{c}\mathbf{R}^{\mathbf{2}} \\
(\mathbf{N}=\mathbf{4 3})\end{array}$ & $\begin{array}{c}\mathbf{R M S E} \% \\
(\mathbf{N}=\mathbf{2 9})\end{array}$ & $\begin{array}{c}\mathbf{R}^{\mathbf{2}} \\
(\mathbf{N}=\mathbf{4 3})\end{array}$ & $\begin{array}{c}\mathbf{R M S E \%} \\
(\mathbf{N}=\mathbf{2 9})\end{array}$ \\
\hline Simple linear & 0.29 & 49.25 & 0.25 & 58.52 \\
Quadratic & 0.29 & 50.40 & 0.25 & 60.62 \\
Logarithmic & 0.33 & 49.40 & 0.28 & 58.85 \\
\hline
\end{tabular}

The models for CPA versus biomass are not mentioned as $\mathrm{R}^{2}$ and $\mathrm{RMSE} \%$ value are same with the models of CPA versus carbon (Table 4).

\section{Error in CPA delineation}

A set of rule, i.e., rotating image to $180^{\circ}$, visualized in RGB 132, fixing scale at 1:250 was followed consistently for the manual delineation of CPA on low pass filtered pansharpened image. But precise digitisation also depends on canopy architecture (Browning et al., 2009). The shape of crown of the broadleaf species (Fig. 6) is very irregular compared to needleleaved trees. Because of irregular pattern, manual digitisation becomes too difficult to avoid error.

In intermingled canopy situation, where the crowns of two or more individual trees touched or overlapped, it was found difficult to identify from a top-down perspective whether the image object represent two, three or more tree crowns. This problem was handled with the help of information of sample plot location, intermingled canopy trees outline in the JPEG print out of image and the coordinates of the measured trees.

Another important point that caused error in CPA delineation was the fuzziness of boundary of the canopy (Fig. 6) in the image. In the forest, reflectance of other vegetation, i.e., ground cover, understory shrubs, trees further creates noise for the reflectance of top canopy dominant trees. The boundary of the dominant trees is no longer remained crisp. We can imagine the crisp boundary of tree crown in the case of roadside plantation where trees are usually lopped, well trained and surrounded with man-made geographic objects. 


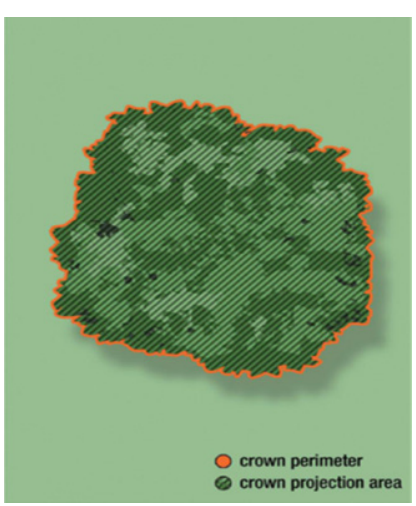

(a)

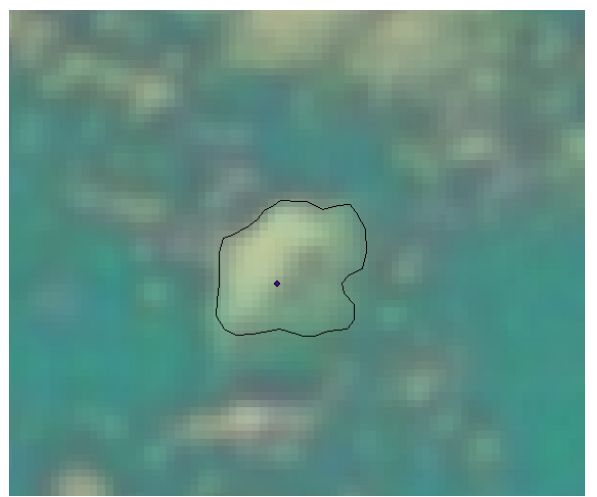

(b)

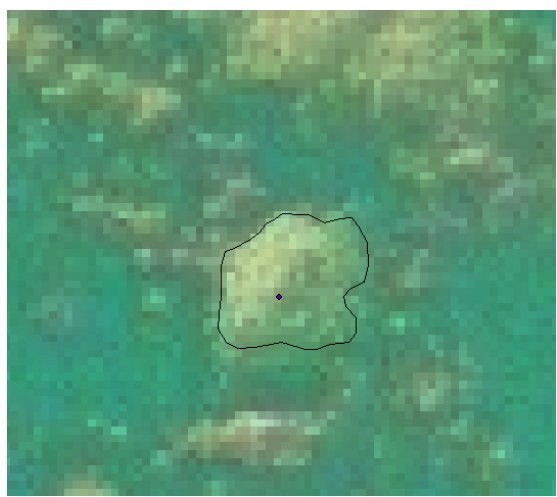

(c)

Fig. 6: (a) CPA; (b) Stand alone tree CPA digitised on filtered image; (c) The stand alone tree CPA on unfiltered image

The month of image acquisition also contributed to fuzziness of the boundary of dominant tree canopy. The image was acquired in November when the selected dominant species, which are semi-deciduous, start shedding their leaves. As the amount of leaves in the tree crown decreases, understory vegetation reflectance get space to appear in the scene. This further exacerbates the fuzziness of tree crown edges.

The third important point is the presence of shadow in the image (Fig. 6b). Mountainous topography further causes to increase the shadow in the scene. Shadow particularly obscured canopy area (Wulder et al., 2004) as shown in figures 6 (a) and (b).

\section{Sources of error and its influence on modelling steps}

Table 5 indicates the sources of error and its influence on different steps of modelling the relationship between CPA and above-ground tree carbon. Propagation of error in modelling steps from different sources causes poor prediction of carbon from CPA.

\section{Conclusion}

The above-ground carbon stock of intermingled canopy trees cannot be estimated by using manually delineated CPA from GeoEye Satellite Image. The simple linear regression models having the least error are not applicable for the prediction of above-ground tree carbon stock of broadleaved forest in hilly terrain as the models have poor $\mathrm{R}^{2}$ which is mainly caused by error in vertical projection area of tree canopy because of low sun angle and shadow in the scene. This is further exacerbated by the mountainous topography of the study area. In addition, manual delineation of CPA has been affected by the fuzziness tree crown boundary in the image.

\section{Recommendations}

- Local species specific allometric equation should be used to improve model accuracy for the prediction of above-ground tree carbon.

- It is recommended to validate CPA (delineated from very high resolution satellite images) using field measured CPA.

- Large dataset of tree parameters need to be

Table 5: Sources of error and its influence on modelling steps

\begin{tabular}{|c|c|c|c|c|}
\hline Modelling steps & Sources of error an & its influence on the $\mathrm{m}$ & odelling steps & \\
\hline Image acquisition & High sun angle & $\begin{array}{l}\text { Shadow (oblique } \\
\text { image) }\end{array}$ & $\begin{array}{l}\text { Shadow } \\
\text { (mountainous } \\
\text { topography) }\end{array}$ & \\
\hline CPA delineation & $\begin{array}{l}\text { Irregular crown } \\
\text { shape }\end{array}$ & $\begin{array}{l}\text { Understory vegetation } \\
\text { / fuzziness of canopy } \\
\text { boundary }\end{array}$ & Shadow & Satellite image \\
\hline CPA versus DBH & Satellite image & CPA delineation & & \\
\hline CPA versus Carbon & Allometric equation & $\mathrm{CPA}$ versus $\mathrm{DBH}$ & & \\
\hline
\end{tabular}


collected for the development of reliable regression models.

- Further studies are required to estimate aboveground carbon stock of trees accurately using other remote sensing method like airborne LiDAR.

\section{References}

Asner, G. P. 2009. Tropical forest carbon assessment: integrating satellite and airborne mapping approches. Environmental Letters 4: 11.

Bartelink, H. H. 1996. Allometric relationships on biomass and needle area of Douglas-fir. Forest Ecology and Management 86 (1-3): 193-203.

Browning, D. M., Archer, S. R. and Byrne, A. T. 2009. Field validation of 1930 s aerial photography: What are we missing? Journal of Arid Environments 73 (9): 844-853.

Brown, S. 2002. Measuring carbon in forests: current status and future challenges. Environmental Pollution 116 (3): 363-372.

Chiba, Y. 1998. Architectural analysis of relationship between biomass and basal area based on pipe model theory. Ecological Modelling 108 (1-3): 219-225.

CIFOR., FAO., UNDP. and UNEP. 2009. Reporting REDD: A journalist's guide to the role of forests in combating global climate change. UK.

Clark, D. B. and Clark, D. A. 2000. Landscapescale variation in forest structure and biomass in a tropical rain forest. Forest Ecology and Management 137 (1-3): 185-198.

FAO. 2013. Media Centre, Official webpage of FAO. Available on line at http://www.fao. org/news/story/pt/item/40893/icode/en/; last accessed on August 9, 2013.

Gibbs, H. K., Brown, S., Niles, J. O. and Foley, J. A. 2007. Monitoring and estimating tropical forest carbon stocks: making REDD a reality. Environmental Research Letters 2 (4): 1-13.

Gill, S. J., Biging, G. S. and Murphy, E. C. 2000. Modelling conifer tree crown radius and estimating canopy cover. Forest Ecology and Management 126 (3): 405-416.

Gonzalez, P., Asner, G. P., Battles, J., Lefsky,
M. A., Waring, K. M. and Palace, M. 2010. Forest carbon densities and uncertainties from Lidar, Quick Bird, and field measurements in California. Remote Sensing of Environment 114 (7): 1561-1575.

Hedl, R., Svatek, M., Dancak, M., Rodzay, A. W., Salleh, A. B. M. and Kamariah, A. S. 2009. A new technique for inventory of permanent plots in tropical forests: a case study from lowland dipterocarp forest in Kuala Belalong, Brunei Darussalam. Blumea 54 (1-3): 124-130.

Husch, B., Beers, T. W. and Kershaw, J. A. 2003. Forest Mensuration (Fourth edition). Hoboken: Wiley and Sons, USA.

IPCC. 2006. Guidelines for National Greenhouse Gas Inventories. Official webpage of IPCC. Available at $h t t p: / / w w w$. ipcc-nggip.iges.or.jp/public/2006gl/pdf/4 Volume4/V4_04_Ch4_Forest_Land.pdf; last accessed on May 5, 2011.

Larocque, G. R. 2000. Performance of young jack pine trees originating from two different branch angle traits under different intensities of competition. Annals of Forest Science 57 (7): 635-649.

Leboeuf, A., Beaudoin, A., Fournier, R. A., Guindon, L., Luther, J. E. and Lambert, M. C. 2007. A shadow fraction method for mapping biomass of northern boreal black spruce forests using Quick Bird imagery. Remote Sensing of Environment 110 (4): 488-500.

Mitchell, J. E. and Popovich, S. J. 1997. Effectiveness of basal area for estimating canopy cover of Ponderosa pine. Forest Ecology and Management 95 (1): 45-51.

Panta, M., Kim, K. and Joshi, C. 2008. Temporal mapping of deforestation and forest degradation in Nepal: Applications to forest conservation. Forest Ecology and Management 256 (9): 1587-1595.

Patenaude, G., Milne, R. and Dawson, T. P. 2005. Synthesis of remote sensing approaches for forest carbon estimation: reporting to the Kyoto Protocol. Environmental Science and Policy 8 (2): 161-178.

UNFCCC. 2010. UNFCCC. Official webpage of UNFCCC. Available at http://unfccc.int/ 2860.php; last accessed on May 7, 2011. 
Winer, B. J. 1962. Statistical Principle in Experiment Design. Mc GRAW-Hill Book Company, London, UK.

Wulder, M. A., Whitea, J. C. ,Niemannb, K. O. and Nelsonc, T. 2004. Comparison of airborne and satellite high spatial resolution data for the identification of individual trees with local maxima filtering. International Journal of Remote Sensing 25 (11): 2225-2232. 